\title{
Major dietary patterns and cardiovascular risk factors among young Brazilian adults
}

\author{
Maria Teresa A. Olinto $\cdot$ Denise P. Gigante • \\ Bernardo Horta $\cdot$ Vera Silveira $\cdot$ Isabel Oliveira • \\ Walter Willett
}

Received: 17 January 2011/ Accepted: 24 May 2011/Published online: 17 June 2011

(C) The Author(s) 2011. This article is published with open access at Springerlink.com

\begin{abstract}
Purpose Diet is one of the most important modifiable risk factors for cardiovascular diseases. The scientific literature has consistently shown the effects of certain diets on health; however, given the variety of cultures and dietary habits across the world, it is likely that much remains to be learned about dietary patterns and health outcomes. We assessed the associations between main dietary patterns and cardiovascular risk factors among 4,202 young Brazilian adults in a cross-sectional analysis.

Methods In a principle components analysis, two main dietary patterns were identified: common Brazilian and processed food. As outcomes, we examined body mass index (BMI), waist circumference (WC), systolic blood pressure (SBP), diastolic blood pressure (DBP), total
\end{abstract}

M. T. A. Olinto $(\bowtie)$

Post-graduate Programme in Collective Health,

University of Vale do Rio dos Sinos, Av. Unisinos 950,

São Leopoldo, RS 93022-000, Brazil

e-mail: mtolinto@unisinos.br

D. P. Gigante · B. Horta · V. Silveira · I. Oliveira

Post-graduate Programme in Epidemiology, Federal University

of Pelotas, Mal. Deodoro 1160, $3^{\circ}$ fl, Pelotas, RS 96020-220,

Brazil

W. Willett

Department of Nutrition,

Harvard School of Public Health, Boston, MA, USA

W. Willett

Channing Laboratory, Department of Medicine,

Brigham and Women's Hospital, Boston, MA, USA

W. Willett

Harvard Medical School, Boston, MA, USA cholesterol, HDL cholesterol (HDL-c), and LDL cholesterol (LDL-c). Means, crude, and adjusted $\beta$ coefficients and $95 \%$ CIs were estimated according to quintiles of dietary patterns.

Results Common Brazilian scores were inversely associated with BMI, WC, LDL-c, HDL-c, and total cholesterol values among men. Among women, inverse association trends were observed with SBP, DBP, LDL-c, HDL-c, and total cholesterol. The processed food pattern was positively associated with LDL-c, HDL-c, total cholesterol, BMI, and WC values among the men. Among the women, the processed food pattern was not significantly associated with cardiovascular risk factors.

Conclusions In conclusion, our findings confirm that diet has an important role on health during early adulthood. The common Brazilian pattern showed generally healthier trends regarding CVD risk factors, but the ultimate effects on risk of risk of disease are unclear because of the inverse relation with HDL-c levels.

Keywords Cardiovascular disease - Risk factors . Dietary patterns · Young adult

\section{Introduction}

Cardiovascular diseases are now the major contributor to the burden of disease in most countries. Diet is one of the most important modifiable risk factors for cardiovascular diseases [1]. Although the majority of the worldwide cardiovascular disease burden occurs in low and middleincome countries, few studies on the effects of diet have been conducted in these areas. The scientific literature has consistently shown the effects of certain diets on health, such as deleterious effect of the Western type of diet and 
benefits of plant-based, prudent, or Mediterranean diets [2, 3-7]. However, given the variety of cultures and dietary habits across the world, it is likely that much remains to be learned about dietary patterns and health outcomes.

The dietary pattern approach has been shown to be a powerful means for summarizing nutrient and food intake to depict the whole diet. Thus, this approach reflects dietary preferences, reflects actual consumption, identifies groups at nutritional risk, and has provided associations with greater consistency and strength than has been possible for single foods. It can also improve understanding of the role of diet in chronic disease, and the results can be easily translated into public health recommendations [8-14].

Most studies of dietary patterns and cardiovascular disease risk factors have been carried out among older adults or elderly people [15-18]; few have investigated diet and cardiovascular risk factors in early adulthood [19] or among populations in developing countries. Understanding the associations between dietary habits and health outcomes among young adults may help to promote healthy changes in dietary behavior that might be maintained throughout adulthood, with the aim of ensuring healthy aging.

The objective of the present study was to assess the associations between major dietary patterns and cardiovascular risk factors among young Brazilian adults. The common Brazilian and the processed food dietary patterns have been identified as major patterns in an earlier study using principal component analysis [20].

\section{Subjects and methods}

This study includes young adults, mean age 23 years, from the 1982 birth cohort conducted in the city of Pelotas, Southern Brazil. In 1982, the original study included 5,913 live-born infants. In the 2004-2005 follow-up, a total of 4,297 young adults were found and interviewed. Also, the system for monitoring mortality had identified 282 deaths since birth. Up to now, the follow-up rate is $77.4 \%$; moving out from Pelotas to seek a job was the main reasons for dropping-out. The methodology of the follow-up has been published elsewhere [21].

\section{Study population}

Among the cohort members located in 2004-2005 followup, we studied 4,202 subjects (2,161 men and 2,041 women) whose dietary patterns were described in a previous analysis [20]. Serum HDL cholesterol was assessed in 3,741 subjects, and total cholesterol and LDL cholesterol were assessed in 2,378 subjects. The subject sub-samples were randomly selected due to the available resources for the laboratory analysis.

Dietary assessment

Information on diet was collected during interviews carried out in 2004-2005. Briefly, usual intake over the past year was assessed by a semi-quantitative, interviewer-administered food frequency questionnaire (FFQ) with 82 food items. Food items from the FFQ were classified into 47 groups by combining foods that were similar in nutrient profile and represented particular dietary habits of the Southern Brazilian population.

Intake of energy and nutrients was computed by multiplying the consumption frequency of each food by the nutrient content of the specific portion. Energy and nutrient intake were estimated from the Brazilian Table of Food Composition (TACO) [22]. Alternatively, the USDA National Nutrient Database for Standard ReferenceRelease 20 tables [23] was used for the foods not found in the Brazilian table.

\section{Assessment of CVD risk factors}

BMI (body mass index) was calculated by weight divided by height in meters squared. Weight and height measures were obtained following the recommendations of Lohmann et al. [24].Weight was measured using portable electronic scales (Seca uniscale ${ }^{\circledR}$, Germain) with $100 \mathrm{~g}$ precision. Aluminum anthropometers were used to obtain height measures. Waist circumference (WC) was measured at the narrowest part of the trunk in the middle point between the rib cage and the iliac crest. An inextensible tape was applied directly to uncovered skin, with the subjects standing and at the end of expiration. Systolic and diastolic blood pressures were measured using a digital wrist sphygmomanometer (OMRON HEM-629). Two measurements were made, at least 20 min apart (at the start and end of the interview), with the subjects resting in the seated position with the right arm supported at the heart level.

At the end of the interview, the subjects were invited to visit the research laboratory to give a blood sample. Another home visit was made, with the aim of obtaining blood samples from the interviewees who did not go to the laboratory. Blood samples were collected by venipuncture. High-density lipoprotein cholesterol was analyzed for all 3,741 subjects whose blood samples were stored at minus $80^{\circ} \mathrm{C}$, and total cholesterol was analyzed for 2,378 subjects. Total cholesterol and triglycerides were measured by enzymatic method. High-density lipoprotein (HDL-c) cholesterol was measured by the using an ultrasensitive direct method, using a Selectra 2 analyzer (Merck). Lowdensity lipoprotein cholesterol (LDL-c) levels were 
calculated for subjects who had triacylglycerol concentrations $\leq 400 \mathrm{mg} / \mathrm{dL}(4.52 \mathrm{mmol} / \mathrm{L})$ according to Friedwald's equation. All serum lipids were expressed in $\mathrm{mg} / \mathrm{dL}$. Because the timing of blood collection was not standardized according to fasting or time of day, blood glucose and triglycerides were not used as outcomes in this analysis.

The study was approved by the Ethics Committee of the Medical Faculty of Federal University of Pelotas. Written informed consent was obtained from all subjects prior to the interview.

\section{Statistical analyses}

We conducted a principal components factor analysis (PCA) to derive major dietary patterns. The factors were rotated by an orthogonal (Varimax) transformation. The number of factors retained was based on the following criteria: components with an eigenvalue $>1$, scree plot test, and the interpretability of the factors. Food items were considered to load on a factor if they had an absolute correlation $\geq .30$. Two main patterns with larger variance explained, 8.6 and $7.1 \%$, were identified and labeled as common Brazilian and as processed food. The first pattern, common Brazilian was composed by sugar, white bread, coffee, butter/margarine, rice, and black beans. The second pattern, the processed food, was composed by red and processed meats, salty snacks, French fries, beer, soda, and other processed foods. More methodological details of the dietary patterns have been published elsewhere [20]. Standardized factor score coefficients (mean of zero and a standard deviation of 1), i.e., the individual values of the factors, were estimated by regression approach (after PCA) and saved for the each dietary pattern in SPSS version 16.0 (SPSS inc., Chicago, IL, USA). We categorized the standardized score based on quintiles and used the first quintile as the reference group in the subsequent analyses.

The CVD risk factors were analyzed as continuous dependent variables: body index mass (BMI), waist circumference (WC), systolic blood pressure (SBP), diastolic blood pressure (DBP), total cholesterol, HDL cholesterol, and LDL cholesterol. Common Brazilian and processed food dietary patterns were the independent variables. Subjects were categorized based on quintiles of dietary pattern score. Means and $95 \%$ confidence interval of CVD outcomes were calculated across quintiles of dietary patterns. Simple and multiple linear regression models were undertaken separately for women and men. Common Brazilian and processed food patterns were entered in separate models. Triglyceride values were natural logtransformed (ln $\mathrm{mg} / \mathrm{L}$ ) for greater symmetry prior to undertaking statistical analyses. In addition to crude models, multivariable models were used to assess relations between dietary patterns and CVD outcomes. These models were I adjusted for education level (years of schooling), family income (per capita of minimum monthly wage), energy intake (kcal/day), and physical activity (in metabolic equivalent tasks $\mathrm{min} /$ weak). Physical activity was assessed using the International Physical Activity Questionnaire (IPAQ, long version) [25]. Crude and adjusted $\beta$ coefficients and 95\% CI were presented. Linear trends for the association were assessed by assigned the values of 1-5 to the quintiles and computing the $p$-value for each trend with multiple regression analysis. All tests were two tailed, and $p$-values $<0.05$ were considered significant. Statistical analyses were performed using STATA version 9.0 (Stata Corp., College Station, TX, USA).

\section{Results}

Among 4,202 subjects, men and women had the same mean age (23 year) and distribution of skin color $(24 \%$ non-white). Women had higher education (greater than 12 years of schooling), $19 \%$ versus $12 \%$, than men. Men reported higher levels of leisure-time physical activity than women ( $217 \pm 301$ vs. $80 \pm 186 \mathrm{~min} /$ week). Men also had a higher prevalence (23.4 vs. $18.0 \%)$ of overweight (BMI between 25 and $29.9 \mathrm{~kg} / \mathrm{m}^{2}$ ), while women had a higher prevalence (7.7 vs. $9.2 \%$ ) of obesity (BMI $\geq 30 \mathrm{~kg}$ / $\mathrm{m}^{2}$ ). We compared the main characteristics between the total 4,202 cohort members included in our study and the two sub-samples-one included 3,741 blood samples for assessing HDL cholesterol values and another included 2,378 blood samples for assessing total cholesterol and LDL cholesterol values, and no differences were found among them (data not shown).

Table 1 shows energy and macronutrient profile according to the quintiles for common Brazilian and processed food dietary patterns. All components present linear trend through the quintiles, with increasing or decreasing trend. Fiber intake (g/day) was positively associated with both the common Brazilian and processed food scores.

Table 2 shows means and regression coefficients for CVD risk factors according to the quintiles of common Brazilian dietary pattern in men. The common Brazilian pattern was inversely related to BMI, WC, HDL-c, LDL-c, and total cholesterol, even in the multivariate analysis. Table 3 shows the mean and regression coefficient values according to the quintiles of common Brazilian dietary pattern in women. Although there was weak overall inverse association between the common Brazilian dietary pattern and $\mathrm{BMI}$ or $\mathrm{WC}$, the associations in the top quintiles were not statistically significant. On the other hand, significantly lower levels of SBP and DBP were observed in the highest quintile. Strong inverse associations with the common 
Table 1 Score points, energy and macronutrient profile (mean and SD) according to dietary pattern quintiles

\begin{tabular}{|c|c|c|c|c|c|c|}
\hline \multirow[t]{2}{*}{ Nutrients } & \multicolumn{6}{|l|}{ Mean (SD) } \\
\hline & Q1 & Q2 & Q3 & Q4 & Q5 & $p$-value* \\
\hline \multicolumn{7}{|l|}{ Score points } \\
\hline Common Brazilian & $-1.19(0.32)$ & $-0.58(0.12)$ & $-0.17(0.14)$ & $0.44(0,76)$ & $1.50(0.76)$ & $<.0001$ \\
\hline Processed food & $-1.12(0.26)$ & $-0.59(0.12)$ & $-0.17(0.13)$ & $0.35(0.18)$ & $1.50(0.89)$ & $<.0001$ \\
\hline \multicolumn{7}{|l|}{ Energy intake (cal/day) } \\
\hline Common Brazilian & $2921.7(1370.7)$ & $3230.2(1412.4)$ & $3476.6(1457.6)$ & $3782.0(1559.6)$ & $4482.3(1712.4)$ & $<.0001$ \\
\hline Processed food & $2818.3(1301)$ & $3112.2(1369.4)$ & $3410.9(1376.5)$ & $3840.1(1458.4)$ & $4712.5(1735.9)$ & $<.0001$ \\
\hline \multicolumn{7}{|l|}{ Protein intake $(\%)$} \\
\hline Common Brazilian & $14.9(3.6)$ & $14.0(3.8)$ & $13.2(3.1)$ & $12.9(3.2)$ & $12.2(3.0)$ & $<.0001$ \\
\hline Processed food & $12.5(3.2)$ & $13.0(3.1)$ & $13.4(3.3)$ & $14.0(3.6)$ & $14.4(7.7)$ & $<.0001$ \\
\hline \multicolumn{7}{|l|}{ Total fat $(\%)$} \\
\hline Common Brazilian & $29.4(7.8)$ & $28.3(8.3)$ & $27.0(8.3)$ & 24.7 (7.6) & $22.7(7.5)$ & $<.0001$ \\
\hline Processed food & $22.7(8.9)$ & $25.6(8.6)$ & $26.9(7.6)$ & $27.8(7.4)$ & $29.1(7.1)$ & $<.0001$ \\
\hline \multicolumn{7}{|l|}{ Carbohydrate (\%) } \\
\hline Common Brazilian & 55.7 (7.9) & $57.6(8.2)$ & $59.8(8.2)$ & $62.3(7.6)$ & $65.0(7.6)$ & $<.0001$ \\
\hline Processed food & $64.7(9.0)$ & $61.3(8.5)$ & $59.7(7.8)$ & $58.2(7.6)$ & $56.5(7.6)$ & $<.0001$ \\
\hline \multicolumn{7}{|l|}{ Fiber (g/day) } \\
\hline Common Brazilian & $31.8(20.5)$ & $37.0(20.3)$ & $43.0(22.5)$ & $52.0(27.3)$ & $64.6(32.2)$ & $<.0001$ \\
\hline Processed food & $45.8(28.4)$ & $41.8(34.3)$ & $43.0(25.1)$ & $46.7(29.4)$ & $51.1(29.0)$ & $<.0001$ \\
\hline
\end{tabular}

$* p$-value for linearity

Common Brazilian dietary pattern: composed by rice, black beans, sugar, coffee, white bread, butter/margarine

Processed food dietary pattern: composed by red and processed meats, salty snacks, French fries, beer, soda, and others processed food

Brazilian dietary pattern and serum levels of LDL-c, HDL-c, and total cholesterol were observed.

Means and regression coefficients for CVD risk factors according to processed food dietary pattern are shown in Tables 4 and 5. Among men (Table 4), the processed food pattern was directly associated with BMI and WC. Higher scores for the processed food pattern were positively associated with higher values of HDL-c and total cholesterol. Among women (Table 5), no significant overall associations between processed food and CVD risk factors were observed. WC was lower in the highest quintile of processed food compared to the first quintile $(\beta=$ $-1.85 \mathrm{~cm} ;$ IC95\% -3.60 to -0.11$)$.

\section{Discussion}

We assessed the relationships between cardiovascular risk factors and major dietary patterns among young adults, aged 23 years, enrolled in the 1982 Pelotas Birth Cohort Study, a Southern city in Brazil. The common Brazilian dietary pattern was associated with lower levels of total and LDL cholesterol, but also lower levels of HDL cholesterol. This pattern was also associated with lower systolic and diastolic blood pressure, especially among women. On the other hand, the processed food pattern was associated with higher BMI, WC, and total and LDL cholesterol values, but also higher HDL cholesterol levels among men. This pattern was not related to CVD risk factors among women. Although the common Brazilian dietary pattern was generally associated with variables predicting lower risk of cardiovascular disease, the ultimate effects on risk of risk of disease are unclear because of the inverse relation with HDL-c levels.

Although dietary patterns are not completely comparable across countries and cultures, our processed food pattern is similar to the Western type of diet among the American population [5, 12, 26, 27]. The processed food pattern was composed of a varied list of foods, such as hot dog, hamburger, beer, red meat, processed meat, snacks, soda, mayonnaise, pizza, barbecue, French fries, canned vegetables (pickles), and liver, but the highest factor loadings were attributed to meat and meat products [20]. In addition, Western-type diets usually also include foods like potatoes, eggs, soda, and sweets. The processed food pattern contained higher quintiles of processed food scores, higher amounts of total energy, and higher percentages of energy from total fat (Table 1). Therefore, we 
Table 2 Means, linear regression analysis ( $\beta$ coefficient), and 95\% confidence intervals for quintiles of common Brazilian dietary pattern in predicting cardiovascular disease risk factors in men, 1982 Pelotas Birth Cohort Study (follow-up 2004-2005), $n=2,161$

\begin{tabular}{|c|c|c|c|c|c|c|}
\hline & \multicolumn{6}{|l|}{ Common Brazilian } \\
\hline & Q1 & Q2 & Q3 & Q4 & Q5 & $p$-value \\
\hline \multicolumn{7}{|l|}{ BMI $\left(\mathrm{kg} / \mathrm{m}^{2}\right)$} \\
\hline Mean & $25.1(24.7 ; 25.5)$ & $24.3(23.9 ; 24.7)$ & $23.6(23.3 ; 24.0)$ & $23.5(23.1 ; 23.9)$ & $22.9(22.5 ; 23.2)$ & \\
\hline Crude $(\beta)$ & Ref. & $-.83(-1.39 ;-.27)$ & $-1.47(-2.03 ;-.92)$ & $-1.59(-2.15 ;-1.03)$ & $-2.27(-2.82 ;-1.7)$ & \\
\hline Adjusted $(\beta)$ & Ref. & $-.69(-1.26 ;-.12)$ & $-1.23(-1.81 ;-.65)$ & $-1.29(-1.89 ;-.7)$ & $-1.79(-2.42 ;-1.16)$ & $<.0001^{\mathrm{c}}$ \\
\hline \multicolumn{7}{|l|}{$\mathrm{WC}(\mathrm{cm})$} \\
\hline Mean & $84.1(83.1 ; 85.2)$ & $81.5(80.6 ; 82.5)$ & $80.8(79.9 ; 81.7)$ & $80.1(79.1 ; 81.0)$ & $78.9(78.0 ; 79.8)$ & \\
\hline Crude $(\beta)$ & Ref. & $-2.6(-3.99 ;-1.21)$ & $-3.36(-4.73 ;-1.98)$ & $-4.06(-5.46 ;-2.66)$ & $-5.22(-6.60 ;-3.83)$ & \\
\hline Adjusted $(\beta)$ & Ref. & $-2.09(-3.51 ;-.67)$ & $-2.53(-3.97 ;-1.08)$ & $-3.1(-4.58 ;-1.61)$ & $-3.78(-5.35 ;-2.22)$ & $<.0001^{\mathrm{c}}$ \\
\hline \multicolumn{7}{|l|}{$\mathrm{SBP}\left(\mathrm{mm} \mathrm{hg}^{3}\right)$} \\
\hline Mean & $124.9(123.4 ; 126.4)$ & $122(120.7 ; 123.3)$ & $122.4(121.1 ; 123.7)$ & $124.2(122.9 ; 125.6)$ & $124.1(122.8 ; 125.4)$ & \\
\hline Crude $(\beta)$ & Ref. & $-2.91(-4.90 ;-.91)$ & $-2.46(-4.44 ;-.49)$ & $-.66(-2.67 ; 1.34)$ & $-.81(-2.80 ; 1.18)$ & \\
\hline Adjusted $(\beta)$ & Ref. & $-2.9(-4.94 ;-.86)$ & $-2.43(-4.51 ;-.35)$ & $-.62(-2.76 ; 1.52)$ & $-.65(-2.91 ; 1.60)$ & $.012^{\mathrm{d}}$ \\
\hline \multicolumn{7}{|l|}{$\mathrm{DBP}\left(\mathrm{mm} \mathrm{hg}{ }^{3}\right)$} \\
\hline Mean & $77.6(76.4 ; 78.8)$ & $74.6(73.6 ; 75.7)$ & $74.7(73.7 ; 75.8)$ & $75.6(74.5 ; 76.7)$ & $76.2(75.1 ; 77.2)$ & \\
\hline Crude $(\beta)$ & Ref. & $-2.95(-4.56 ;-1.34)$ & $-2.87(-4.46 ;-1.28)$ & $-1.98(-3.60 ;-.36)$ & $-1.43(-3.03 ; .18)$ & \\
\hline Adjusted $(\beta)$ & Ref. & $-3.01(-4.66 ;-1.37)$ & $-2.74(-4.41 ;-1.06)$ & $-1.61(-3.33 ; .11)$ & $-.68(-2.49 ; 1.13)$ & $<.001^{\mathrm{d}}$ \\
\hline \multicolumn{7}{|c|}{ LDL-c $(\mathrm{mg} / \mathrm{dL})^{\dagger}$} \\
\hline Mean $^{a}$ & $67.9(64.2 ; 71.6)$ & $70.2(66.9 ; 73.4)$ & $69.5(66.2 ; 72.8)$ & $65(61.5 ; 68.5)$ & $63.8(60.6 ; 67)$ & \\
\hline Crude $(\beta)$ & Ref. & $2.30(-2.62 ; 7.22)$ & $1.63(-3.31 ; 6.57)$ & $-2.91(-7.99 ; 2.18)$ & $-4.10(-9.02 ; .82)$ & \\
\hline Adjusted $(\beta)$ & Ref. & $2.89(-2.17 ; 7.96)$ & $2.41(-2.82 ; 7.64)$ & $-2.25(-7.68 ; 3.19)$ & $-3.36(-8.94 ; 2.23)$ & $.035^{\mathrm{c}}$ \\
\hline \multicolumn{7}{|l|}{ HDL-c (mg/dL) } \\
\hline Mean $^{\mathrm{a}}$ & $53.5(52.3 ; 54.8)$ & $52.3(51.1 ; 53.4)$ & $50.8(49.7 ; 51.9)$ & $50.8(49.7 ; 51.9)$ & $50.8(49.7 ; 51.8)$ & \\
\hline Crude $(\beta)$ & Ref. & $-1.27(-2.97 ; .42)$ & $-2.74(-4.40 ;-1.08)$ & $-2.73(-4.43 ;-1.03)$ & $-2.78(-4.46 ;-1.11)$ & \\
\hline Adjusted $(\beta)$ & Ref. & $-.57(-2.31 ; 1.17)$ & $-1.83(-3.58 ;-.08)$ & $-1.88(-3.69 ;-.07)$ & $-1.83(-3.72 ; .06)$ & $<.026^{\mathrm{c}}$ \\
\hline \multicolumn{7}{|c|}{ Cholesterol (mg/dL) } \\
\hline Mean $^{a}$ & $149.7(145.3 ; 154.2)$ & $148.9(145 ; 152.9)$ & $148.2(144.2 ; 152.1)$ & $144(139.8 ; 148.2)$ & $141.7(137.7 ; 145.6)$ & \\
\hline Crude $(\beta)$ & Ref. & $-.79(-6.72 ; 5.13)$ & $-1.57(-7.51 ; 4.37)$ & $-5.74(-11.86 ; .38)$ & $-8.08(-14 ;-2.16)$ & \\
\hline Adjusted $(\beta)$ & Ref. & $.3(-5.79 ; 6.38)$ & $.24(-6.03 ; 6.51)$ & $-3.97(-10.49 ; 2.56)$ & $-5.69(-12.42 ; 1.03)$ & $<.0001^{\mathrm{c}}$ \\
\hline
\end{tabular}

Adjusted $(\beta)$ : multivariable models adjusted for family income, education, energy intake, and physical activity

${ }^{a}$ For LDL and total cholesterol $n=1,176$ men and for HDL cholesterol $n=1,874$ men

b calculated for subjects who had triglyceride concentrations $\leq 400 \mathrm{mg} / \mathrm{dL}$ ( $4.52 \mathrm{mmol} / \mathrm{L}$ ) according to Friedwald's equation

c $p$-value for linear trend in multivariable model

${ }^{\mathrm{d}} p$-value for heterogeneity test in multivariable model

hypothesized that this food pattern would have adverse effects on CVD biomarkers. However, adverse relationships were observed only in men, and among men, a positive association was seen with HDL-c, again casting uncertainty about the ultimate effect on the risk of cardiovascular disease.

Our study showed that there was a positive relationship between the processed food dietary pattern and BMI and WC among the men. This was maintained after adjustment for potential confounders such as physical activity, energy intake, and socioeconomic characteristics. Extreme quintile comparison yielded increased WC $(\beta=2.65 ; 95 \% \mathrm{CI}$ : $1.15 ; 4.15)$ for the processed food pattern among the men.
There is no clear consistency among other studies. Nettleton and colleagues observed that diets that included processed meat and higher fat scores were associated with higher BMI and WC in both genders in late adulthood [16]. High intake of potatoes, meat, and meat products was associated with significantly increased WC among Greek adults [28]. Among American adult women, the Westerntype diet may contribute toward long-term weight gain [26]. Among the women in our study, the processed food dietary pattern was not found to be associated with either BMI or WC. The traditional dietary pattern identified in young Finns, which was described as posing a greater threat to cardiovascular health than Western food, did not 


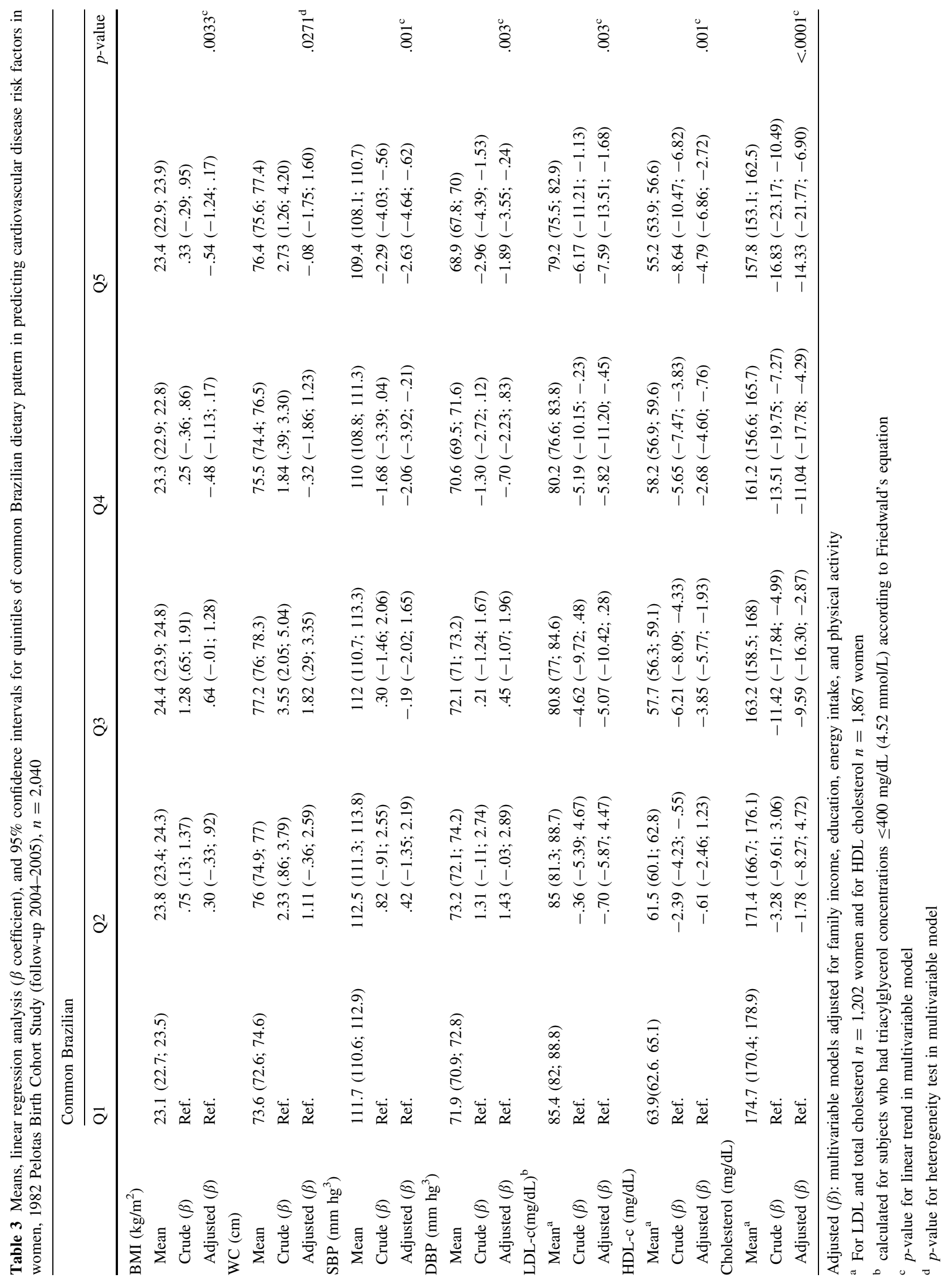


Table 4 Means, linear regression analysis ( $\beta$ coefficient), and 95\% confidence intervals for quintiles of processed food dietary pattern in predicting cardiovascular disease risk factors in men, 1982 Pelotas Birth Cohort Study (follow-up 2004-2005), $n=2161$

\begin{tabular}{|c|c|c|c|c|c|c|}
\hline & \multicolumn{6}{|l|}{ Processed food } \\
\hline & Q1 & Q2 & Q3 & Q4 & Q5 & $p$-value \\
\hline \multicolumn{7}{|l|}{ BMI $\left(\mathrm{kg} / \mathrm{m}^{2}\right)$} \\
\hline Mean & $23.4(23.0 ; 23.9)$ & $23.7(23.3 ; 24.1)$ & $23.7(23.3 ; 24.2)$ & $24.1(23.7 ; 24.4)$ & $24.0(23.6 ; 24.3)$ & \\
\hline Crude $(\beta)$ & Ref. & $.31(-.30 ; .93)$ & $.33(-.28 ; .94)$ & $.66(.08 ; 1.24)$ & $.55(-.02 ; 1.11)$ & \\
\hline Adjusted $(\beta)$ & Ref. & $.35(-.26 ; .96)$ & $.43(-.18 ; 1.04)$ & $.87(.28 ; 1.46)$ & $1.00(.39 ; 1.60)$ & $<.0001^{\mathrm{c}}$ \\
\hline \multicolumn{7}{|l|}{$\mathrm{WC}(\mathrm{cm})$} \\
\hline Mean & 79.8 (78.6; 80.9) & $80.7(79.7 ; 81.7)$ & $80.7(79.7 ; 81.7)$ & $81.3(80.5 ; 82.2)$ & $81.6(80.8 ; 82.4)$ & \\
\hline 'Crude $(\beta)$ & Ref. & $.95(-.57 ; 2.47)$ & $.92(-.60 ; 2.43)$ & $1.56(.12 ; 3)$ & $1.81(.41 ; 3.22)$ & \\
\hline Adjusted $(\beta)$ & Ref. & $.98(-.52 ; 2.49)$ & $1.06(-.45 ; 2.57)$ & $1.92(.46 ; 3.38)$ & $2.65(1.15 ; 4.15)$ & $<.0001^{\mathrm{c}}$ \\
\hline \multicolumn{7}{|l|}{$\mathrm{SBP}\left(\mathrm{mm} \mathrm{hg^{3 } )}\right.$} \\
\hline Mean & $124.3(122.7 ; 126)$ & $123.2(121.7 ; 124.6)$ & $124(122.6 ; 125.5)$ & $123.3(122 ; 124.5)$ & $123(121.8 ; 124.1)$ & \\
\hline Crude $(\beta)$ & Ref. & $-1.15(-3.31 ; 1.02)$ & $-.31(-2.47 ; 1.84)$ & $-1.08(-3.13 ; .97)$ & $-1.37(-3.37 ; .63)$ & \\
\hline Adjusted $(\beta)$ & Ref. & $-1.20(-3.37 ; .97)$ & $-.36(-2.53 ; 1.82)$ & $-1.17(-3.28 ; .93)$ & $-1.42(-3.59 ; .74)$ & $.632^{\mathrm{d}}$ \\
\hline \multicolumn{7}{|l|}{ DBP $\left(m m h^{3}\right)$} \\
\hline Mean & $76.2(74.9 ; 77.5)$ & $75.8(74.6 ; 76.9)$ & $76.2(75.1 ; 77.4)$ & $75.4(74.3 ; 76.4)$ & $75.1(74.2 ; 76.1)$ & \\
\hline Crude $(\beta)$ & Ref. & $-.39(-2.14 ; 1.36)$ & $.04(-1.70 ; 1.78)$ & $-.80(-2.46 ; .85)$ & $-1.02(-2.64 ; .59)$ & \\
\hline Adjusted $(\beta)$ & Ref. & $-.29(-2.04 ; 1.46)$ & $.22(-1.53 ; 1.97)$ & $-.51(-2.21 ; 1.18)$ & $-.50(-2.24 ; 1.25)$ & $.878^{\mathrm{d}}$ \\
\hline \multicolumn{7}{|c|}{ LDL-c $(\mathrm{mg} / \mathrm{dL})^{\mathrm{b}}$} \\
\hline Mean $^{\mathrm{a}}$ & $64.3(60.5 ; 68.2)$ & $63.7(60.2 ; 67.2)$ & $68.5(64.9 ; 72)$ & $70(66.8 ; 73.2)$ & $68.6(65.6 ; 71.6)$ & \\
\hline Crude $(\beta)$ & Ref. & $-.62(-5.80 ; 4.57)$ & $4.16(-1.07 ; 9.39)$ & $5.69(.69 ; 10.69)$ & $4.24(-.63 ; 9.10)$ & \\
\hline Adjusted $(\beta)$ & Ref. & $-.80(-6.01 ; 4.41)$ & $4.15(-1.17 ; 9.47)$ & $6.02(.85 ; 11.18)$ & $4.96(-.33 ; 10.25)$ & $.007^{\mathrm{c}}$ \\
\hline \multicolumn{7}{|l|}{ HDL-c (mg/dL) } \\
\hline Mean $^{\mathrm{a}}$ & $49.6(48.3 ; 51)$ & $51.1(49.9 ; 52.3)$ & $51.4(50.2 ; 52.5)$ & $51.9(50.8 ; 52.9)$ & $52.8(51.8 ; 53.8)$ & \\
\hline Crude $(\beta)$ & Ref. & $1.43(-.36 ; 3.21)$ & $1.72(-.04 ; 3.48)$ & $2.24(.54 ; 3.93)$ & $3.15(1.49 ; 4.81)$ & \\
\hline Adjusted $(\beta)$ & Ref. & $1.23(-.55 ; 3.01)$ & $1.41(-.35 ; 3.18)$ & $1.75(.01 ; 3.49)$ & $2.57(.79 ; 4.36)$ & $.006^{\mathrm{c}}$ \\
\hline \multicolumn{7}{|c|}{ Cholesterol (mg/dL) } \\
\hline $\operatorname{Mean}^{\mathrm{a}}$ & $140.2(135.6 ; 144.8)$ & $143.3(139.1 ; 147.5)$ & $147.6(143.3 ; 151.9)$ & $148.6(144.8 ; 152.5)$ & $149.7(146.1 ; 153.3)$ & \\
\hline Crude $(\beta)$ & Ref. & $3.10(-3.14 ; 9.35)$ & $7.41(1.12 ; 13.70)$ & $8.44(2.41 ; 14.47)$ & $9.49(3.64 ; 15.34)$ & \\
\hline Adjusted $(\beta)$ & Ref. & $2.66(-3.60 ; 8.93)$ & $7.20(.82 ; 13.58)$ & $8.71(2.50 ; 14.91)$ & $10.23(3.88 ; 16.58)$ & $<.0001^{\mathrm{c}}$ \\
\hline
\end{tabular}

show any association with BMI, either in men or in women [19]. Furthermore, no associations between a diet high in fat and sugar and either BMI or WC were found in Australian adolescents [29].

The processed food dietary pattern showed a positive linear trend with total and LDL cholesterol among the men, but not among the women. Diets characterized by meat and processed meat have showed a worse lipid profile, i.e., increased LDL cholesterol or total cholesterol $[15,16]$. The traditional diet of young Finns, which consists of foods that differ from the Western diet but which are also characterized by elevated intake of high fat and high sodium food, was shown to produce elevated total and LDL cholesterol in both genders [19]. Meat intake has been reported as a cardiovascular risk factor, not only as a major source of saturated fat but also through heme iron provided by meat [30]. Higher consumption of heme iron was associated with an increased risk of myocardial infarction among men [31]. Although higher quintiles of the processed food pattern were correlated with higher percentages of saturated fat intake, it is noteworthy that less than $10 \%$ of the calories in the higher quintiles came from saturated fat, i.e., within the traditional target. Also higher quintiles were correlated with increased mono- and polyunsaturated fat and lower 
Table 5 Means, linear regression analysis ( $\beta$ coefficient), and 95\% confidence intervals for quintiles of processed food dietary pattern in predicting cardiovascular disease risk factors in women, 1982 Pelotas Birth Cohort Study (follow-up 2004-2005), $n=2040$

\begin{tabular}{|c|c|c|c|c|c|c|}
\hline & \multicolumn{6}{|l|}{ Processed food } \\
\hline & Q1 & Q2 & Q3 & Q4 & Q5 & $\begin{array}{l}p \text { - } \\
\text { value }\end{array}$ \\
\hline \multicolumn{7}{|l|}{ BMI $\left(\mathrm{kg} / \mathrm{m}^{2}\right)$} \\
\hline Mean & $24(23.6 ; .24 .4)$ & $23.6(23.1 ; 24)$ & $23.7(23.2 ; 24.1)$ & $23.3(22.9 ; 23.8)$ & $22.9(22.3 ; 23.4)$ & \\
\hline Crude $(\beta)$ & Ref. & $-.41(-.99 ; .17)$ & $-.31(-.89 ; .28)$ & $-.62(-1.25 ; .01)$ & $-1.11(-1.79 ;-.43)$ & \\
\hline Adjusted $(\beta)$ & Ref. & $-.08(-.66 ; .49)$ & $.17(-.42 ; .76)$ & $-.02(-.67 ; .63)$ & $-.32(-1.06 ; .41)$ & $752^{\mathrm{d}}$ \\
\hline \multicolumn{7}{|l|}{ WC (cm) } \\
\hline Mean & $76.8(75.9 ; 77.7)$ & $75.8(74.8 ; 76.9)$ & $75.4(74.4 ; 76.5)$ & $75.1(73.9 ; 76.2)$ & $73.8(72.5 ; 75.1)$ & \\
\hline Crude $(\beta)$ & Ref. & $-.95(-2.33 ; .43)$ & $-1.36(-2.75 ; .02)$ & $-1.74(-3.24 ;-.23)$ & $-2.99(-4.62 ;-1.37)$ & \\
\hline Adjusted $(\beta)$ & Ref. & $-.22(-1.59 ; 1.14)$ & $-.37(-1.77 ; 1.02)$ & $-.55(-2.09 ; .99)$ & $-1.85(-3.60 ;-.11)$ & $.068^{\mathrm{c}}$ \\
\hline \multicolumn{7}{|c|}{$\mathrm{SBP}\left(\mathrm{mm} \mathrm{hg}^{3}\right)$} \\
\hline Mean & $112.3(111.2 ; 113.4)$ & $110(108.8 ; 111.2)$ & $111.1(109.9 ; 112.3)$ & $111.2(109.8 ; 112.6)$ & $111.1(109.5 ; 112.7)$ & \\
\hline Crude $(\beta)$ & Ref. & $-2.3(-3.92 ;-.68)$ & $-1.15(-2.79 ; .48)$ & $-1.1(-2.87 ; .68)$ & $-1.17(-3.09 ; .74)$ & \\
\hline Adjusted $(\beta)$ & Ref. & $-2.11(-3.68 ;-.53)$ & $-1.12(-2.74 ; .49)$ & $-.63(-2.41 ; 1.14)$ & $-.06(-2.08 ; 1.95)$ & $.106^{\mathrm{d}}$ \\
\hline \multicolumn{7}{|c|}{$\mathrm{DBP}\left(\mathrm{mm} \mathrm{hg^{3 } )}\right.$} \\
\hline Mean & $72(71 ; 72.9)$ & $70.3(69.4 ; 71.3)$ & 71.7 (70.7; 72.7) & $71.5(70.4 ; 72.7)$ & $71(69.7 ; 72.3)$ & \\
\hline Crude $(\beta)$ & Ref. & $-1.62(-2.97 ;-.27)$ & $-.29(-1.65 ; 1.06)$ & $-.45(-1.92 ; 1.02)$ & $-1(-2.6 ; .59)$ & \\
\hline Adjusted $(\beta)$ & Ref. & $-1.55(-2.87 ;-.23)$ & $-.29(-1.64 ; 1.06)$ & $.02(-1.47 ; 1.51)$ & $.31(-1.38 ; 2.00)$ & $103^{\mathrm{d}}$ \\
\hline \multicolumn{7}{|c|}{ LDL-c $(\mathrm{mg} / \mathrm{dL})^{\mathrm{b}}$} \\
\hline Mean $^{\mathrm{a}}$ & $81.3(78.2 ; 84.4)$ & $82.5(79 ; 85.9)$ & $82.9(79.3 ; 86.4)$ & $82.4(78.4 ; 86.5)$ & $82.4(77.7 ; 87)$ & \\
\hline Crude $(\beta)$ & Ref. & $1.16(-3.48 ; 5.81)$ & $1.54(-3.18 ; 6.26)$ & $1.22(-3.96 ; 6.21)$ & $1.05(-4.52 ; 6.63)$ & \\
\hline Adjusted $(\beta)$ & Ref. & $.83(-3.86 ; 5.52)$ & $.83(-4.03 ; 5.69)$ & $.68(-4.65 ; 6.01)$ & $.41(-5.67 ; 6.49)$ & $997^{\mathrm{d}}$ \\
\hline \multicolumn{7}{|c|}{ HDL-c (mg/dL) } \\
\hline Mean $^{\mathrm{a}}$ & $58.4(57.2 ; 59.6)$ & $60(58.7 ; 61.3)$ & $59.7(58.4 ; 61)$ & $60.2(58.7 ; 61.7)$ & $59.2(57.5 ; 60.9)$ & \\
\hline Crude $(\beta)$ & Ref. & $1.59(-.17 ; 3.34)$ & $1.29(-.48 ; 3.05)$ & $1.8(-.12 ; 3.72)$ & $.77(-1.31 ; 2.85)$ & \\
\hline Adjusted $(\beta)$ & Ref. & $.5(-1.2 ; 2.19)$ & $.01(-1.73 ; 1.75)$ & $.3(-1.62 ; 2.21)$ & $-.4(-2.58 ; 1.78)$ & $.933^{\mathrm{d}}$ \\
\hline \multicolumn{7}{|c|}{ Cholesterol (mg/dL) } \\
\hline Mean $^{\mathrm{a}}$ & $164.4(160.5 ; 168.4)$ & $166.5(162.1 ; 170.9)$ & $167.2(162.6 ; 171.7)$ & $166.6(161.5 ; 171.7)$ & 165.7 (159.8; 171.6) & \\
\hline Crude $(\beta)$ & Ref. & $2.05(-3.88 ; 7.98)$ & $2.74(-3.27 ; 8.76)$ & $2.18(-4.3 ; 8.66)$ & $1.25(-5.85 ; 8.35)$ & \\
\hline Adjusted $(\beta)$ & Ref. & $.74(-5.19 ; 6.66)$ & $.49(-5.64 ; 6.63)$ & $.18(-6.55 ; 6.91)$ & $-.48(-8.15 ; 7.20)$ & $.998^{\mathrm{d}}$ \\
\hline \multicolumn{7}{|c|}{ Adjusted $(\beta)$ : multivariable models adjusted for family income, education, energy intake, and physical activity } \\
\hline \multicolumn{7}{|c|}{${ }^{a}$ For LDL and total cholesterol $n=1,202$ women and for HDL cholesterol $n=1,867$ women } \\
\hline \multirow{2}{*}{\multicolumn{7}{|c|}{$\begin{array}{l}\text { b calculated for subjects who had triglyceride concentrations } \leq 400 \mathrm{mg} / \mathrm{dL}(4.52 \mathrm{mmol} / \mathrm{L}) \text { according to Friedwald's equation } \\
\text { c } p \text {-value for linear trend in multivariable model }\end{array}$}} \\
\hline & & & & & & \\
\hline \multicolumn{7}{|c|}{${ }^{\mathrm{d}} p$-value for heterogeneity test in multivariable model } \\
\hline
\end{tabular}

percentages of calories from carbohydrates (data not presented). Therefore, this could partially explain the higher levels of HDL cholesterol in the upper quintiles of the processed food pattern [32]. Sadakane et al. [15] found a similar relationship with higher levels of HDL cholesterol in a pattern of high meat consumption. The Western diet showed a significant and positive correlation with HDL among adult men in the Health Professionals Follow-up Study [12]. Because the associations for LDL-c and HDL-c would predict opposite risks for coronary heart disease, and the relation of the processed food pattern to other intermediate variables such as thrombotic tendency and arrhythmia were not studied, we cannot predict the effect of this dietary pattern to risk of cardiovascular disease.

Regarding the common Brazilian dietary pattern, we did not have any prior hypothesis regarding the direction of the association with CVD risk factors. Higher quintiles of the common Brazilian dietary pattern showed significant linear trend of decreasing BMI and total and LDL cholesterol values in both genders, yet the trend for WC was observed only among the men. Among the women, significant inverse trends were also observed regarding 
systolic and diastolic blood pressures. Nevertheless, the common Brazilian dietary pattern was composed of foods that contained refined carbohydrates (i.e., white bread and rice) and also "empty calories" (i.e., sugar). Such nutritional contents have been associated with adverse effects on health, as summarized elsewhere [33]. On the other hand, some specific foods or combination of foods could partially explain the beneficial associations with CVD risk factors. For example, coffee, which is part of the common Brazilian pattern, might have benefits for health. Recent studies have suggested that heavy consumption (six or more cups per day) was associated with a lower risk of fatal CHD in both genders [34]. Among women, the results suggest that coffee consumption may modestly reduce the risk of stroke [35]. In a previous analysis, we observed that $71 \%$ of the cohort members consumed at least one serving of coffee every day (data not published), and the usual Brazilian intake is filtered coffee. Furthermore, consumption of black beans, which present high fiber content, could be partially responsible for the beneficial effects. Beans have traditionally been the main source of fiber in the Brazilian diet [36], and the combination of rice and beans has been shown to be protective against obesity among Brazilian adults [37]. In our study, the highest quintile of the common Brazilian diet showed a high value of fiber intake ( $64.6 \pm 7.6 \mathrm{~g}$ /day). In general, soluble fiber consumption decreases serum cholesterol and LDL cholesterol and is accompanied by reduction in serum HDL [38]. At least three inter-related factors could account for the lower HDL in the higher common Brazilian diet consumer. First, a fall in serum HDL cholesterol is observed when carbohydrate is consumed along with high-fiber diets [39]. Related to this, HDL cholesterol reductions also could be attributed to an unfavorable effect of lower-fat and high-carbohydrate diets [32]. The upper quintiles of the common Brazilian pattern showed very high-carbohydrate intake $(>60 \%$ of total energy intake), and low fat intake ( $<23 \%$ of total intake). Moreover, long-term exposure, i.e., chronic intake of a high-carbohydrate diet, is also associated with lower concentration of HDL [40]. The common Brazilian diet is composed of popular foods, such as simple rice, beans, and bread, and is consumed since childhood through adulthood. A better understanding could be obtained from measuring the small lipoprotein particles of HDL; however, it was not in scope of our study, and some caution is necessary to interpret those findings.

Although high-fiber diets have potential benefits regarding weight loss [41], our findings of lower BMI among both men and women in the higher quintiles of common Brazilian should be interpreted with caution. Previous analyses have shown that the common Brazilian pattern was more likely to be followed by subjects with low socioeconomic status (SES) [20]. However, SES was identified as an effect modifier on the relationship between obesity and gender [42] among the members of this cohort, i.e., lower SES was shown to be a protective factor against obesity in men and a strong risk factor among women, in comparison with higher SES. Although our multivariate models were adjusted for SES characteristics, physical activity, and energy intake for both genders, there may have been other potential confounders associated with CVD risk factors and with dietary patterns that might be different in men and women, for which we were unable to adjust.

Some points need to be addressed. We focused our analysis on the dietary pattern approach, because we believe that this is more closely related to real life, in which people eat meals consisting of a variety of foods instead of single nutrients. In this approach, both known and unknown interactions between nutrients are taken into account [2]. Another point relates to the nature of the two dietary patterns investigated: the common Brazilian pattern might be regarded as home-prepared food, in contrast to the manufactured foods that characterize the processed food pattern. In general, these patterns showed opposite associations: the former showed mainly healthier trends and the latter mainly showed harmful trends with regard to CVD risk factors.

Finally, our study had some methodological limitations. First, we performed a cross-sectional analysis, although the subjects belong to a birth cohort study and have been followed for almost 25 years. Complete data on diet and biomarker information were collected only during the eighth follow-up in 2004-2005. Reverse causality might be present in our results, but we supposed that lipid profiles or blood pressure levels were unknown among young adults by themselves, and consequent changes to their diet would not be expected. The exception was with regard to dietary habits and anthropometric, which might have accounted for our findings among women. Secondly, we assessed the nutrient components based on the Brazilian Food Composition Table (TACO) [22], and in the cases of foods not found in the Brazilian table, we used the USDA National Nutrient Database for Standard Reference as an alternative [23]. However, few specific foods were missing from these tables. In addition, imprecise dietary measurements could potentially have influenced our findings, but in fact, random errors in diet measurements might lead to a lack of association, but not the reverse.

In conclusion, our findings suggest that diet has an important role in health from early adulthood onwards. The common Brazilian pattern showed generally healthier trends regarding CVD risk factors, but improvements to the nutritional quality of this dietary pattern appear to be desirable and deserve further investigation. 
Acknowledgments This article is based on data from the study "Pelotas birth cohort, 1982" conducted by Postgraduate Program in Epidemiology at Universidade Federal de Pelotas. The 1982 birth cohort study is currently supported by the Welcome Trust Initiative entitled Major Awards for Latin America on Health Consequences of Population Change. Previous phases of the study were supported by the International Development Research Center, The World Health Organization, Overseas Development Administration, European Union, National Support Program for Centers of Excellence (PRO$\mathrm{NEX}$ ), the Brazilian National Research Council (CNPq), and Brazilian Ministry of Health. We are also grateful to Brazilian National Research Council (CNPq) (scholarship process n. 308833/2006-6) and Brazilian Coordination of Improvement of Higher Education Personnel (CAPES) (scholarship process n. 4343/07-7).

Conflict of interest All authors declared have no conflicts of interest.

Open Access This article is distributed under the terms of the Creative Commons Attribution Noncommercial License which permits any noncommercial use, distribution, and reproduction in any medium, provided the original author(s) and source are credited.

\section{References}

1. World Health Organization (2008) Report of the World Health Organization Study Group. Diet nutrition and prevention of chronic diseases

2. Hu F (2003) Plant-based foods and prevention of cardiovascular disease: an overview. Am J Clin Nutr 78:544S-551S

3. van Dam RM, Rimm EB, Willett WC, Stampfer MD, Hu FB (2002) Dietary patterns and risk for type 2 diabetes mellitus in US men. Ann Intern Med 1363:201-209

4. Brunner E, Mosdol A, Whitte DR, Martikainen P, Stafford M, Shipley M, Marmot M (2008) Dietary patterns and 15 years risks of major coronary events, diabetes, and mortality. Am J Clin Nutr 87:1414-1421

5. Hu FB, Rimm EB, Stampfer MJ, Ascheiro A, Spiegelman D, Willett WC (2000) Prospective study of major dietary patterns and risk of coronary heart disease in men. Am J Clin Nutr 72:912-921

6. Sofi F, Abbate R, Gensini G, Casini A (2010) Accruing evidence on benefits of adherence to the Mediterranean diet on health: an updated systematic review and meta-analysis. Am J Clin Nutr 92:1189-1196

7. Trichopoulou A, Costacou T, Bamia C, Trichopoulos D (2003) Adherence to a mediterranean diet and survival in a Greek population. New Eng J Med 34826:2599-2608

8. Jacques P, Tucker K (2001) Are dietary patterns useful for understanding the role of diet in chronic disease? Am J Clin Nutr 73:1-2

9. Kant AK (2004) Dietary patterns and health outcomes. Am Diet Assoc 1044:615-635

10. Hu FB (2002) Dietary pattern analysis: a new direction in nutritional epidemiology. Curr Opin Lipidol 131:3-9

11. Martinez ME, Marshall JR, Sechrest L (1998) Invited commentary: factor analysis and the search for objectivity. Am J Epidemiol 1481:17-19

12. Fung T, Rimm E, Spiegelman D, Rifai N, Tofler G, Willett J, Hu F (2001) Association between dietary patterns and plasma biomarkers of obesity nas cardiovascular disease risk. Am J Clin Nutr 73:61-67

13. Slattery M, Boucher K, Caan B, Potter J, Ma K (1998) Eating patterns and risk of colon cancer. Am J Epidemiol 148:4-16
14. Newby PK, Tucker KL (2004) Empirically derived eating patterns using factor or cluster analysis: a review. Nutr Rev 625:177-203

15. Sadakane A, Tsutsumi A, Gotoh T, Ishikawa S, Ojima T, Kario K, Nakamura Y, Kayaba K (2008) Dietary patterns and levels of blood pressure and serum lipids in Japanese population. J Epidem 182:58-67

16. Nettleton J, Polak J, Tracy R, Burke GDJ (2009) Dietary patterns and incident cardiovascular disease in the multi-ethnic study of atherosclerosis. Am J Clin Nutr 90:647-654

17. Berg C, Lappas G, Strandhagen E, Wolk A, Torén K, Rosengren A, Aires N, Thelle D, Lissner L (2008) Food patterns and cardiovascular disease risk factors: the Swedish INTERGENE research program. Am J Clin Nutr 88:289-297

18. Tourlouki E, Matalas A, Panagiotakos D (2009) Dietary habits and cardiovascular disease risk in middle-aged and elderly populations: a review evidence. Clin Intervet Aging 4:319-330

19. Mikkilä V, Räsänen L, Raitakari $O$, Marniemi J, Pietinen $P$, Rönnemaa T, Viikari J (2007) Major dietary patterns and cardiovascular risk factors from childhood to adulthood. The cardiovascular risk in young finns study. Br J Nutrition 98:218-225

20. Olinto M, Willett J, Gigante D, Victora C (2010) Sociodemographic and lifestyle characteristics in relation to dietary patterns among young Brazilian adults. Public Health Nutr 14:150-159

21. Victora CG, Barros AJ (2006) Cohort profile: the 1982 Pelotas (Brazil) Birth cohort study. Int J Epidemiol 352:237-242

22. TACO (2006) [Brazilian table of food composition]/Núcleo de Estudos e Pesquisas em Alimentação-NEPA, 2nd edn. Universidade Estadual de Campinas-UNICAMP_-Versão II, Campinas

23. USDA (2007) United States department of agriculture. Food search for window, Version 1.0, database SR20

24. Lohman T, Roche A, Martorell R (1988) Anthropometric standardization reference manual champaign: human kinetics

25. Craig CL, Marshall AL, Sjostrom M et al (2003) International physical activity questionnaire: 12-country reliability and validity. Med Sci Sports Exerc 35:1381-1395

26. Schulze M, Fung T, Manson J, Willett J, Hu F (2006) Dietary patterns and changes in body weight in women. Obesity 148:1444-1452

27. Kerver J, Yang E, Bianchi L, Song W (2003) Dietary patterns associated with risk factors for cardiovascular disease in healthy US adults. Am J Clin Nutr 786:1103-1110

28. Panagiotakos D, Pitsavos C, Skoumas Y, Stefanadis C (2007) The association between food patterns and metabolic syndrome using principal components analysis: the Attica study. Am Diet Assoc 1007:979-987

29. McNaughton S, Ball K, Mishra G, Crawford D (2008) Dietary patterns of adolescents and risk of obesity and hypertension. J Nutr 138:364-370

30. Bernstein A, Sun Q, Hu F, Stampfer M, Manson J, Willett W (2010) Major dietary protein sources and risk of coronary heart disease in women. Circulation 1229:876-883

31. Ascheiro A, Willett J, Rimm E, Giovannucci E, Stampfer M (1994) Dietary iron intake and risk of coronary disease among men. Circulation 89:969-974

32. Katan M (1998) Effect of low-fat diets on plasma high density lipoprotein concentrations. Am J Clin Nutr 68(suppl):573S-576S

33. Willett WC (2008) Overview and perspective in human nutrition. Asia Pac J Clin Nutr 17S1:1-4

34. Lopez-Garcia E, van Dam R, Willett J, Rimm E, Manson J, Stampfer M, Rexrode K, Hu F (2006) Coffee consumption and coronary heart disease in men and women: a prospective cohort study. Circulation 113:2045-2053

35. Lopez-Gracia E, Rodriquez-Artalejo F, Rexrode K, Logroscino G, Hu FB, van Dam RM (2010) Coffee consumption and risk of stroke in women. Circulation 119:1116-1123 
36. Mattos L, Martins I (2000) Dietary fibre consumption in an adult population. Rev Saúde Pública 34:50-55

37. Sichieri R (2002) Dietary patterns and their associations with obesity in the Brazilian city of Rio de Janeiro. Obes Res 101:42-48

38. Anderson J, Hanna T (1999) Impact of non digestible carbohydrate on serum lipoproteins and risk for cardiovascular disease. J Nutr 129:1457S-1466S

39. Mensink R, Katan M (1987) Effect of monounsaturated fatty acids versus complex carbohydrates on high-density lipoproteins in healthy men and women. Lancet 1(8525):122-125
40. West C, Sullivan D, Katan M, Halferkamps I, Van der Torre H (1990) Boys from populations with high-carbohydrate intake have higher fasting triglyceride levels than boys from population with high-fat intake. Am J Epidemiol 1312:271

41. Turkey M, Skeaff C, Mann JI, Cox BD (1998) The effect of a low-fat, high-carbohydrate diet on serum high density lipoprotein cholesterol and triglyceride. Eur J Clin Nutr 52:728-732

42. Gigante D, Minten G, Horta B, Barros F, Victora C (2008) Nutritional evaluation follow-up of the 1982 birth cohort Pelotas, Southern Brazil. Rev Saúde Pública 42(Supl. 2): 60-69 